\title{
Long Term Retention of Deuterium and Tritium in Alcator C-Mod
}

\author{
W. R. Wampler, \\ Sandia National Laboratories, Albuquerque, NM 87185-1056 \\ C. H. Skinner \\ Princeton Plasma Physics Laboratory, Princeton NJ 08543 \\ C. S. Pitcher, B. LaBombard, B. Lipschultz and C. Fiore \\ MIT Plasma Science and Fusion Center, Cambridge MA 02139
}

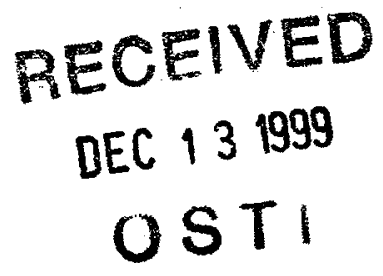

\begin{abstract}
-
We estimate the total in-vessel deuterium retention in Alcator C-Mod from a run campaign of about 1090 plasmas. The estimate is based on measurements of deuterium retained on 22 molybdenum tiles from the inner wall and divertor. The areal density of deuterium on the tiles was measured by nuclearr reaction analysis. From these data, the in-vessel deuterium inventory is estimated to be about $0.1 \mathrm{gram}$, assuming the deuterium coverage is toroidally symmetric. Most of the retained deuterium is on the walls of the main plasma chamber, only about $2.5 \%$ of the deuterium is in the divertor. The $D$ coverage is consistent with a layer saturated by implantation with ions and charge-exchange neutrals from the plasma. This contrasts with tokamaks with carbon plasma-facing components (PFC's) where long-term retention of tritium and deuterium is large and mainly in the divertor due to codeposition with carbon eroded by the plasma. The low deuterium retention in the C-Mod divertor is mainly due to the absence of carbon PFC's in C-Mod and the low erosion rate of $\mathrm{Mo}$.
\end{abstract}

\section{INTRODUCTION}

In,TFTR and JET it has been observed that a large fraction of deuterium and tritium used to fuel plasmas remains in the vessel [1]. This long-term hydrogen isotope retention occurs predominantly by codeposition with carbon eroded from graphite plasma facing components. In a fusion reactor, this high rate of retention would quickly result in unacceptably high in-vessel tritium inventory. The use of metal instead of carbon plasma-facing components should greatly reduce long term tritium retention since erosion and codeposition rates will be much lower for metal than for carbon, especially for high- $Z$ metals. Alcator C-Mod provides a unique opportunity to test this prediction, since it is lined with molybdenum tiles and there are no carbon plasma facing components. Here we present the first estimate of total in-vessel deuterium retention in Alcator CMod. The estimate is based on measurements of deuterium retained on 22 molybdenum tiles from the inner wall and

MAIN AUTHOR AFFILIATION INFORMATION GOES HERE. divertor, after exposure to 1090 plasmas. Deuterium areal density was measured by nuclear reaction analysis. The deuterium concentration versus depth was also examined on selected tiles including one from the outer strike point, a region of high ion flux and net erosion. From these data, the in-vessel deuterium inventory is estimated to be about 0.1 gram, assuming the deuterium coverage is toroidally symmetric. Most of the retained deuterium is on the walls of the main plasma chamber, only about $2.5 \%$ of the retained deuterium is in the divertor. These results are compared with measurements of deuterium and tritium retention in other tokamaks, including JET where most of the retained deuterium is in the divertor. The $\mathrm{D}$ coverage found in C-Mod is much smaller than the D coverage found on graphite limiter and divertor tiles in TFTR, DIII-D, JET and ASDEX Upgrade [1]. The main difference between D retention in C-Mod and tokamaks with graphite divertors or limiters is that in C-Mod there was no significant accumulation of $\mathrm{D}$ with material redeposited by the plasma.

\section{EXPERIMENTAL METHOD}

Molybdenum tiles were installed in the Alcator C-Mod tokamak and exposed to 1090 high power plasmas during the period from November 1995 to March 1996. The location of the tiles during the exposure is shown in Fig.1. Plasma conditions during the exposure were typically, $\mathrm{n}_{\mathrm{e}}=$ (1 to 5 ) $\times 10^{20} \mathrm{~m}^{-3}, \mathrm{I}_{\mathrm{p}}=0.6 \mathrm{MA}$ to $1.2 \mathrm{MA}$. $\mathrm{B}_{\mathrm{T}}=3 \mathrm{~T}$ to $8 \mathrm{~T}$, plasma duration one second, plasma heating power up to 5 $M W$, power flux densities on the divertor plates up to 10 MW $\mathrm{m}^{-2}$. The total integrated time of exposure to tokamak plasmas was about 1200 seconds.

After exposure, the tiles were removed from the tokamak and examined by ion beam analysis. Many of the tiles had a layer of low $Z$ material on the surface. This layer was examined by RBS using $2.5 \mathrm{MeV}^{4} \mathrm{He}$ and $1.7 \mathrm{MeV}^{1} \mathrm{H}$ and by nuclear reaction analysis (NRA) using the ${ }^{11} \mathrm{~B}(\mathrm{p}, \alpha)^{8} \mathrm{Be}$ reaction with ah analysis beam of $650 \mathrm{keV}$ protons [2]. These studies showed the low $Z$ surface layer to consist mainly of boron. In addition to boron, this low- $Z$ surface 


\section{DISCLAIMER}

This report was prepared as an account of work sponsored by an agency of the United States Government. Neither the United States Government nor any agency thereof, nor any of their employees, make any warranty, express or implied, or assumes any legal liability or responsibility for the accuracy, completeness, or usefulness of any information, apparatus, product, or process disclosed, or represents that its use would not infringe privately owned rights. Reference herein to any specific commercial product, process, or service by trade name, trademark, manufacturer, or otherwise does not necessarily constitute or imply its endorsement, recommendation, or favoring by the United States Government or any agency thereof. The views and opinions of authors expressed herein do not necessarily state or reflect those of the United States Government or any agency thereof. 


\section{DISCLAIMER}

Portions of this document may be illegible in electronic image products. Images are produced from the best available original document. 


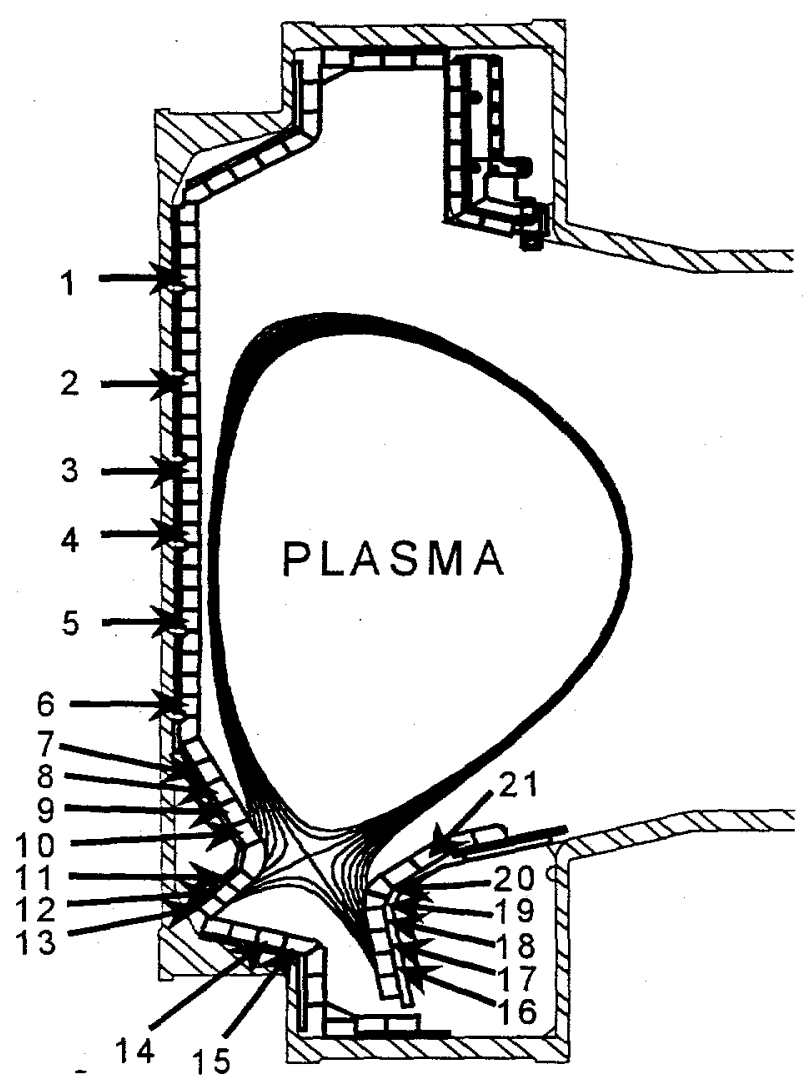

Figure 1 Diagram of Alcator C-Mod showing the location of the tiles. In addition to the numbered tiles, the inner nose tile between tiles 10 and 11 was analyzed for deuterium and boron.

layer could contain small amounts (few percent) of other low $Z$ elements such as carbon and oxygen. The thickness of this boron layer was determined by RBS and is given in figure 2. The boron is present because the vessel was boronized several times during the run campaign to reduce radiated power, which is primarily due to Mo impurities. Boron was deposited by decomposition of diborane in a plasma. Erosion of molybdenum was also measured from the change in depth of a buried chromium marker layer [2].

Deuterium (D) retained on the tiles was measured using ${ }^{3} \mathrm{He}$ (d,p) $\alpha$ nuclear reaction analysis. The areal density of D was determined from the yield of energetic protons using an analysis beam of $700 \mathrm{keV}^{3} \mathrm{He}$. This analysis measures deuterium within about 1 micron of the surface in boron and within about 0.5 micron in Mo. In addition, the $D$ concentration versus depth was examined on selected tiles by measuring the NRA yield versus analysis beam energy up to $2 \mathrm{MeV}$. Fhis method extends the depth of analysis to about $2 \mu \mathrm{m}$ in'Mo.

\section{RESULTS}

Figure 2 shows the measured $\mathrm{D}$ coverage. The error bars for these data indicate the range of values measured at several locations on each tile. Tiles near the outer strike point had the least $D$, consistent with measurements of Mo erosion and $B$ coverage which indicate that the outer strikepoint is a region undergoing net erosion. The depth distribution of deuterium was examined on three tiles; tile

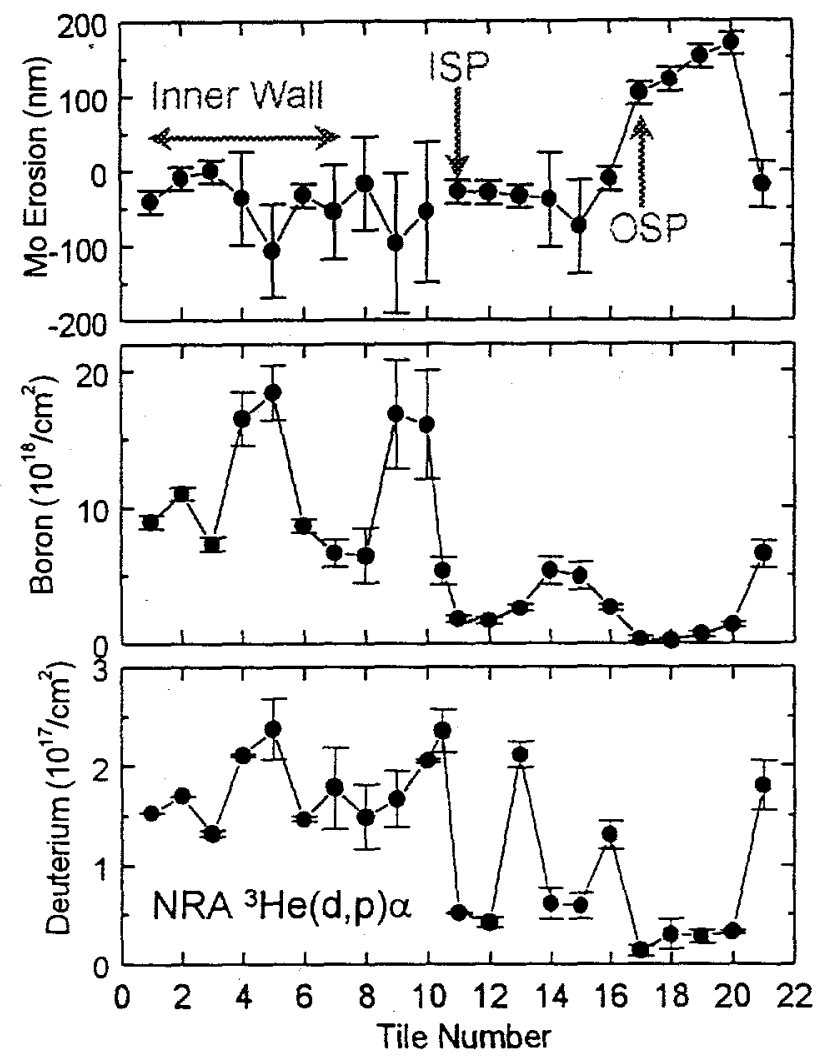

Figure 2 Results from ion-beam analysis. Measured net Mo erosion (top), thickness of surface boron layer (center) and areal density of deuterium (bottom). At the outer strikepoint (tiles 16-20) Mo erosion is highest but boron and $\mathrm{D}$ deposition is lowest.

18 from the outer strikepoint, which had low B and D coverages, and tiles 4 and 10 from the inner wall which had high $B$ and $D$ coverages. On tile 18 the $D$ was all at the surface within the depth resolution $(0.1 \mu \mathrm{m})$ of the measurement. The quantity of $\mathrm{D}$ at depths between $0.2 \mu \mathrm{m}$ and the maximum depth probed ( $2 \mu \mathrm{m}$ in Mo) was less than $10 \%$ of the near-surface coverage, corresponding to a subsurface concentration of $\mathrm{D}$ in Mo below 50 atomic ppm. The $D$ depth profiles on tiles 4 and 10 show the $D$ to be in the boron film, extending to depths of about 1 micron.

The thickness of the boron surface layer is shown in Fig. 2. The outer strikepoint had the least boron. Boron coverage was also relatively low at the inner strikepoint. Elsewhere, boron coverages were higher, ranging up to $1.8 \times 10^{19}$ atoms $/ \mathrm{cm}^{2}$, which corresponds to a physical thickness of $1.4 \mu \mathrm{m}$ assuming the density $2.34 \mathrm{~g} / \mathrm{cm}^{3}$ of elemental boron. On some of the tiles (tile numbers $4,5,7,8,9,10,14,15,21$ ) the boron layer was found to have non-uniform thickness over the region of the analysis beam spot $(1 \times 1 \mathrm{~mm})$. The larger error bars on the boron thickness and Mo erosion shown in Fig. 2 for these tiles are due to the non-uniform boron coverage.

The net Mo erosion was highest on tiles 17-20 at the outer strikepoint (OSP). Here the erosion was 100 to $170 \mathrm{~nm}$. The Mo erosion was much less on all other tiles including the inner strikepoint (ISP).$m$. 
A small amount of tritium is expected to be produced by $\mathrm{D}(\mathrm{D}, \mathrm{p}) \mathrm{T}$ nuclear reactions in the C-Mod plasmas. Tiles 4,5 and 10 , which had higher $D$ coverages, were analyzed for tritium. These measurements were done by counting the rate of emission of tritium betas from the surface of the tiles [3]. This method detects tritium within a near-surface layer from which the low energy tritium betas can escape which is $\sim 1 \mu \mathrm{m}$ for $B$ and $\sim 0.5 \mu \mathrm{m}$ for Mo. These measurements showed that the tritium coverage was below the detection limit which is $\sim 10^{8}$ tritium atoms $/ \mathrm{cm}^{2}$ corresponding to an activity of 5 picoCurie $/ \mathrm{cm}^{2}$. Since we have measurements of both $\mathrm{D}$ and $\mathrm{T}$ areal densities on the same tiles we conclude that the ratio of T/D in the C-Mod tiles is less than $5 \times 10^{-10}$. Most of the tritium should be thermalized in the plasma and thus be retained by the same mechanisms and in the same locations as the $\mathrm{D}[4,5]$. Tritium which is not thermalized but reaches the wall with a significant fraction of its initial $1 \mathrm{MeV}$ kinetic energy, will be implanted into the Mo at depths up to $\sim 5 \mu \mathrm{m}$ and much of this would not be detected by the measurements of surface beta emission.

\section{DISCUSSION}

The increase in inventory of D in C-Mod from the 19951996 nun campaign can be estimated from the measured $D$ coverage on the tiles. The average $\mathrm{D}$ coverage on tiles outside the divertor is $1.8 \pm 0.4 \times 10^{17} \mathrm{D} / \mathrm{cm}^{2}$. The average $\mathrm{D}$ coverage on tiles inside the divertor is: $1.0 \times 10^{0^{-7}} \mathrm{D} / \mathrm{cm}^{2}$ on the inner strikeplate, $0.5 \times 10^{17} \mathrm{D} / \mathrm{cm}^{2}$ on the outer strikeplate, and $0.6 \times 10^{17} \mathrm{D} / \mathrm{cm}^{2}$ in the private flux region between the strikeplates. The in-vessel $D$ inventory is obtained by assuming the $\mathrm{D}$ coverage is toroidally symmetric and multiplying these measured areal densities by the corresponding areas: $16.5 \mathrm{~m}^{2}$ for the main chamber wall outside the divertor, $0.25 \mathrm{~m}^{2}$ for the inner strikeplate, $0.5 \mathrm{~m}^{2}$ for the outer strikeplate and $0.42 \mathrm{~m}^{2}$ for the private flux region. This gives an in-vessel deuterium inventory of 0.10 gram outside the divertor and 0.0025 gram inside the divertor. The $\mathrm{D}$ retention is clearly dominated by the main vessel wall. This $\mathrm{D}$ inventory is about 100 times greater than the vuantity of $D$ in a typical plasma $n_{D} V_{\text {plasma }} \sim 10^{-3}$ gram, assuming $n_{D} \sim n_{e}$ (i.e. $Z \sim 1$ ), with the C-Mod plasma volumg $V_{\text {plasma }} \sim 1 \mathrm{~m}^{3}$.

The measurements of tritium on the tiles can be compared with the quantity of tritium produced during the run campaign. Neutron production by $\mathrm{D}(\mathrm{D}, \mathrm{n})^{3} \mathrm{He}$ nuclear reactions in the plasma was monitored throughout the run campaign [6]. The number of neutrons produced was 8.7 $( \pm 1.6) \times 10^{15}$. This is also the number of tritons produced by $D(D, p) T$ reactions since the cross sections for these two reactionsare similar. The result from the analysis of tritium and deuterium on the tiles that the T/D ratio is $\angle 5 \times 10^{-10}$ together with the estimated inventory of $D$ in the vessel of $\sim$ 0.1 gram $\left(3 \times 10^{22} \mathrm{D}\right.$ atoms) gives the quantity of tritium retained in the vessel $<1.5 \times 10^{13} \mathrm{~T}$ atoms. The fraction of tritium produced which istretained in the C-Mod vessel is therefore estimated to be less than $0: 002$. This is about 100 times smaller than the fraction of fuel retained in tokamaks with carbon PFC's [1].
Previous studies of the retention of tritium produced by $D(D, p) T$ reactions ( $\left.T_{D D}\right)$ in tokamaks with carbon PFC's have found that the fraction of $T_{D D}$ retained is large in such machines. In JT-60U aproximately $50 \%$ of $T_{D D}$ was retained in the wall [7]. Tritium coverage was highest in the divertor in regions where the $\mathrm{D}$ coverage was also high. From measurements of tritium in TFTR graphite tiles it was also estimated that approximately $50 \%$ of $\mathrm{T}_{D D}$ was retained in the TFTR vessel [8]. In DIII-D the fraction of $T_{D D}$ retained was determined to be $10 \%$ or greater [9]. A survey of $\mathrm{T}$ in the first wall of JET was made after the 1986 campaign [10]. The $T$ distributions on the tiles match the patterns of retained $D$, and the overall $T$ inventory was $\sim 4 \%$ of the $T_{D D}$ generated in the campaign, similar to the $\sim 4.5 \%$ of $D$ fuelling retained. In the period 1988-1989 JET operated firstly as an "all-carbon" machine, then with regular periods of beryllium evaporation. and then with solid Be components as well. The percentages of the $D$ fuelling recovered in the pumps on average each day were respectively 45,82 and $78 \%$. The percentages of $T_{D D}$ recovered by the pumps in the same periods were 20,40 and $39 \%$. respectively [1].

Retention of $\mathrm{D}$ and $\mathrm{T}$ in tokamaks occurs predominantly by two mechanisms, direct implantation, and codeposition with material eroded by the plasma $[1,11,12]$. Ions are implanted mainly into surfaces near the divertor strikepoints. The energy of the impinging ions, from their thermal motion and acceleration through the sheath. is a few hundred $\mathrm{eV}$ or less, depending on plasma edge conditions. The shallow depth of implantation at these low energies together with the finite capacity of materials for hydrogen retention and the high incident flux of ions means that these regions quickly approach a steady state condition where the outgoing flux of recycled neutral hydrogen nearly equals the incident ion flux. Near the strikepoint this steady state will be reached in a time much less than the duration of a single discharge. In C-Mod the inner wall of the main plasma chamber may also receive ion flux, particularly during the start-up phase of discharges.

In addition, all plasma-facing surfaces will be implanted with charge-exchange (CX) neutrals from the plasma. The $\mathrm{CX}$ flux varies with location in the vessel and is orders of magnitude lower than the flux of ions at the strikepoint. The CX flux decreases with increasing energy and extends up to a few $\mathrm{keV}$. The $\mathrm{D}$ retention capacity by this mechanism is relatively large because of the large area involved and the greater depth of implantation, due to the higher CX energy. However, due to the low CX flux it may take many discharges for $\mathrm{D}$ retention by this mechanism to reach steady state or saturation. Retention of implanted CX neutrals leads to a wall inventory which is much larger than the amount of $\mathrm{D}$ in the plasma and whose dynamic variations from shot to shot strongly influence fueling of individual discharges $[1,11]$.

Long-term probes exposed at the wall of the main plasma chatmber in JET show eroston at rates consistent with sputtering by $\mathrm{CX}$ neutrals [13]. This process may be a significant source of impurities to the plasma, which would 
also be consistent with the observation that in C-Mod Mo impurities in the plasma are decreased by boronization [14].

Laboratory studies show that $\mathrm{D}$ implanted in carbon is retained until the local $\mathrm{D}$ concentration reaches $\sim 0.4 \mathrm{D} / \mathrm{C}$, after which additional implanted $D$ is not retained $[15,16$, $17,18]$. This leads to saturation of $D$ retention at high fluences where the saturation areal density depends on the thickness of the implanted layer and hence on the energy of the incident $D$. Retention of $D$ with energies between a few hundred $\mathrm{eV}$ and a few $\mathrm{keV}$ saturates layers $\sim 30$ to $100 \mathrm{~nm}$ thick with areal densities in the range from about 1 to $3 \times 10^{17} \mathrm{D} / \mathrm{cm}^{2}[15,16,17,18]$. Retention of D implanted in boron is similar to that of $D$ implanted in carbon [18]. The areal density of $\mathrm{D}$ on the C-Mod tiles is largely within this range, consistent with $\mathrm{D}$ retention in C-Mod $\mathrm{D}$ being mainly due to implantation into the boron film. This is expected since the boron thickness is large compared to the range of the implanted $D$. In other tokamaks, the areal density of $D$ on carbon plasma-facing components in the main plasma chamber, and on regions of carbon limiters or divertor plates undergoing net erosion, is typically also within this range $[12,19]$, which is consistent with $D$ retention in these regions controlled by implantation of ions and CX neutrals. The lower D retention in C-Mod at the divertor strikepoints is where the high ion flux has eroded the boron and exposed the Mo metal surface. Retention of $D$ implanted into Mo is lower than in $B$ or $C[20]$ because $D$ implanted in Mo can thermally diffuse and escape at the

surface [21].

-In tokamaks with carbon PFC's, long term in-vessel inventories of $\mathrm{D}$ and $\mathrm{T}$ are dominated by codeposition of $\mathrm{D}$ and $T$ with carbon eroded by the plasma. $D$ retention by this mechanism may have little noticeable effect on individual discharges, but continues to increase without saturatikg, eventually dominating retention after a large number of discharges. During tritium fueled plasma óperation it was found that about $33 \%$ in JET and $40 \%$ in TFTR of the tritium injected to fuel plasmas was retained in the vessel prior to clean-up procedures [1]. Similar large retention fractions were found for $\mathrm{D}$ fueled plasma operation in TFTR and JET by measurements of fuel balance. And by measurements of $D$ on vessel components which also show that most of the retained $D$ was in codeposited material [1]. In JET, ASDEX-Upgrade and DIIID most of the retained $D$ and $T$ is in the divertor, where thick layers of codeposited carbon accumulate [12, 22, 23]. In contrast, the very small inventory of $D$ in the C-Mod divertor shows that in C-Mod $\mathrm{D}$ retention by codeposition is greatly reduced or absent compared to tokamaks with carbon PFC's.

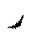

\section{CONCLUSIONS}

The in-vessel D inventory in C-Mod is almost entirely on the wall of the main plasma chamber where $D$

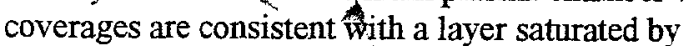
implantation of charge-exchange nelutrals. This leads to the conclusion that in C-Mod the dominant $\mathrm{D}$ retention mechanism is implantation and not codeposition. Retention due to implantation is expected to saturate early in the run campaign, after which the incremental retention should be very low. The fraction of tritium produced which is retained in the C-Mod vessel is estimated to be less than 0.002 . This tritium retention fraction is roughly 100 times smaller than is seen in tokamaks wit carbon PFC's where long-term $\mathrm{D}$ and $\mathrm{T}$ retention is mainly due to codeposition with carbon. The small tritium retention fraction in C-Mod is consistent with implantation rather than codeposition being the dominant long-term fuel retention mechanism in C-Mod and is due to the absence of carbon PFC's in C-Mod and the low erosion rate of Mo.

[1] Issues Arising from Plasma-Wall Interactions in Reactor Class Tokamaks, G. Federici, C. H. Skinner, J. X. Brooks, J. P. Coad, C. grisolia, A A. Haasz, A Hassanein, V. Phillips, C. S. Pitcher, J. Roth, W. R. Wampler, D. G. Whyte, Submitted to Nuclear Fusion.

[2] W. R. Wampler et. al. NNM 266-269 (1999) 217.

[3] W. R. Wampler and B. L. Doyle, Nucl. Instruments and Methods A 349 (1994) 473.

[4] E.V. Carruthers, et al, J. Nucl. Mater. 176 \& 177 (1990) 1027.

[5] R. L. Boivin et. al. Rev. Sci. Instrum. 63 (1992) 4533.

[6] C. L. Fiore and R. L. Boivin. Rev. Sci. Instrum. 66 (1995) 945.

[7] K. Masaki et. al., Fusion Engineering and Design 31 (1996) 181

[8] W. R. Wampler et. al., J. Vac. Sci. Technol. A6 (1988) 2111.

[9] P.L. Taylor,A.G. Kellman, and R.L. Lee. J. Fus. Energy. 12 (1993) 35 .

[10] Goodall, D.H.J., et al, J. Nucl. Mater.162-164 (1989) 1059

[11] P. Andrew et. al., J. Nucl. Mater. 266-269 (1999) 153

[12] J.P. Coad, P.L. Andrew and AT. Peacock, Physica Scripta T81 (1999) 7

[13] Mayer, M., et al., J. Nucl. Mater. 266-269 (1999) 604

[14] Greenwald et.al

[15] Wampler, W.R., Brice, D.K., and Magee, C.W., J. Nucl. Mater. 102 (1981) 304.

[16] Staudenmaier, G., et.al. ,J. Nucl. Mater. 84 (1979) 149

[17] Haasz, A.A., and Davis, J.W., J. Nucl. Mater. 232 (1996) 219.

[18] Doyle, B.L., Wampler, W. R., Brice, D. K and Picraux. S. T., J. Nucl. Mater. 93-94 (1980) $55 \mathrm{I}$.

[19] H. Maier et: al., J. Nucl. Mater. 266-269 (1999) 1003. ASDEX

[20] A. Haasz and J. W. Davis, J. Nucl. Mater. 241-243 (1997) 1076.

[21] H. Katsuta, R. B. McLellan and K Furukawa, J. Phys Chem Solids, 43 (1982) 533.

[22] Maier, H., Krieger, K., Balden, M., Roth, J., J. Nucl. Mater. 266269 (1999) 1003

[23] D.G. Whyte, J.P. Coad, P. Franzen and H. Maier, Nuclear Fusion 39 (1999) 1025.

Sandia is a multiprogram laboratory operated by Sandia Corporation, a Lockheed Martin Company, for the United States Department of Energy under contract DE-AC04-94AL85000.

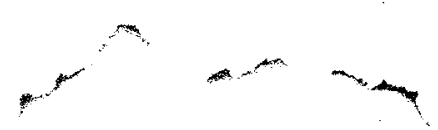

